\title{
Nanobioprobe for the Determination of Pork Adulteration in Burger Formulations
}

\author{
M. E. Ali, ${ }^{1}$ S. Mustafa, ${ }^{2}$ U. Hashim, ${ }^{1}$ Y. B. Che Man, ${ }^{2}$ and K. L. Foo' \\ ${ }^{1}$ Institute of Nano Electronic Engineering (INNE), Universiti Malaysia Perlis, Kangar, 01000 Perlis, Malaysia \\ ${ }^{2}$ Halal Products Research Institute, Universiti Putra Malaysia, Serdang, 43400 Selangor, Malaysia \\ Correspondence should be addressed to S. Mustafa, shuhaimi@biotech.upm.edu.my
}

Received 6 October 2011; Revised 11 November 2011; Accepted 12 November 2011

Academic Editor: Shanfeng Wang

Copyright ( 2012 M. E. Ali et al. This is an open access article distributed under the Creative Commons Attribution License, which permits unrestricted use, distribution, and reproduction in any medium, provided the original work is properly cited.

\begin{abstract}
We report the development of a swine-specific hybrid nanobioprobe through a covalent integration of a fluorophore-labeled 27nucleotide $A l u \mathrm{I}$-fragment of swine cytochrome $\mathrm{b}$ gene to a $3 \mathrm{~nm}$ gold nanoparticle for the determination of pork adulteration in processed meat products. We tested the probe to estimate adulterated pork in ready-to-eat pork-spiked beef burgers. The probe quantitatively detected $1-100 \%$ spiked pork in burger formulations with $\geq 90 \%$ accuracy. A plot of observed fluorescence against the known concentration of AluI-digested pork DNA targets generated a concave curve, demonstrating a power relationship $\left(y=2.956 x^{0.509}\right)$ with a regression coefficient $\left(R^{2}\right)$ of 0.986 . No cross-species detection was found in a standard set of pork, beef, chicken, mutton, and chevon burgers. The method is suitable for the determination of very short-length nucleic acid targets which cannot be estimated by conventional and real-time PCR but are essential for the determination of microRNA in biodiagnostics and degraded DNA in forensic testing and food analysis.
\end{abstract}

\section{Introduction}

In the recent decades, a multitude of reports have been built outlining the detection of meat species in foods [113]. These reports clearly reveal that mitochondrial (mt) DNA is the analyte of choice and that real-time PCR is the analytical method of preference [1-13]. Maternal inheritance, multiple copy numbers, and additional protection by specialized shape of mitochondrial membrane have given $\mathrm{mt}$ genes extraordinary stability to survive in harshly processed food and feeds or compromised samples $[3,6]$. On the other hand, real-time PCR technique is highly automated and allows simultaneous detection and quantification of potential targets from a complex background, eliminating the need of laborious electrophoresis or blotting that are required for conventional PCR [1-13].

A real-time PCR assay with a short-length amplicon is preferred since it provides better amplification and recovery of target DNA from a compromised sample processed under harsh physical and chemical treatments which break down DNA into small fragments [2-8]. Following this observation, real-time PCR assays with amplicon as short as 66 or 76 bps were developed [2]. However, this was achieved with a compromise of assay specificity [5]. A compromised assay leads to artefacts in the final results by cross-amplifying an alien species in heterogeneous mixtures of processed foods. A cross-amplifying assay cannot determine whether there has been a real or contaminated target identification $[3,5,6]$. This has raised the concerns of validity and applicability of PCR assays to authenticate species in highly processed meat products where DNA fragmentation is observed.

Hybrid biomaterials composed of functionalized nanoparticles, covalently [14-17] or noncovalently [18, 19] linked to biomolecules, such as peptides, proteins, and polynucleotides, are particularly interesting and promising for their size-dependent optoelectronic properties and dimensional similarities to biomacromolecules [14-19]. These conjugated biomaterials are potential agents for multiplexed bioassays, material synthesis, ultrasensitive optical detection and imaging, in vivo magnetic resonance imaging (MRI), longcirculating carriers for targeted drug release, and structural scaffolds for tissue engineering [14-19]. 
Thiol-capped gold nanoparticles (GNPs) covalently linked to fluorophore-labeled oligonucleotide through metal-sulfur bonds are shown to detect specific sequences and single-nucleotide mismatches in shorter oligos [1417]. However, such studies are limited to the laboratory level model experiments with synthetic oligotargets. No studies so far have been conducted on the sequence and mismatch detecting power of the fluorophore-labeledoligonanoparticle conjugates in heterogeneous biological or commercial samples. Hybridization profile of such nanobioconjugates is also needed to be explored.

Burger is a special type of restructured comminuted meat products and very popular allover the world [3]. It can be prepared by mixing emulsified ground meat of pork, beef, chicken, lamb, or fish with certain ratios of starch, seasonings, and salts [3]. Replacement of higher value meats by lower value ones is a wide-spread problem in food industry to realize extra economic benefit and also to survive in a highly competitive market $[1-13,16-21]$. Pork is a potential adulterant in beef burger since it is similar in color and texture and also available at cheaper prices [3]. The mixing of pork or its derivatives in food products is a serious matter in the platforms of religions and health because it is not permitted by the Kosher and Halal food laws, its unconscious consumption might ignite allergic reactions, and its high content of cholesterol and saturated fats may initiate cardiovascular diseases [3-13, 16-20]. Thus, reliable, easy-to-perform, and cost-effective methodologies are highly appreciated for the verification of pork adulteration in processed foods.

In this paper, we structurally and functionally integrated a 27-nucleotide AluI-cut segment of swine mitochondrial (mt) cytb gene to a $3 \mathrm{~nm}$ diameter citrate-tannate-coated gold nanocrystal to fabricate a novel class of species-specific nanobioprobe to determine pork in ready-to-consume burger formulations. The method is comparatively cheaper than the real-time PCR and can be applied to analyze highly compromised heterogeneous samples where PCR methods may not work due to breakdown of longer DNA template into smaller fragments.

\section{Materials and Methods}

2.1. Design of Swine-Specific Oligoprobe. We chose a 27-nt AluI-cut fragment (428-454 bp) of swine (Sus scrofa) cytb gene (GenBank accession no. Gu135837.1 in NCBI data base) as a porcine-specific marker. This fragment demonstrated a high degree of polymorphism between the species and similarities within the species by NCBI-BLAST analysis against nonredundant nucleotide collections and also by ClustalW alignment analysis. The probes were customsynthesized with a tetramethyl rhodamine (TMR) dye at the $5^{\prime}$-end and a thiol (SH) function at the $3^{\prime}$-end with a hexyl-A (A6) spacer between them by the Integrated DNA Technologies, USA. The synthetic targets (complementary, noncomplementary, and single mismatched) were supplied by the 1st Base, Malaysia. The probe and oligosequences are shown in Table 1.
2.2. Synthesis of Colloidal Gold Nanoparticles. Small gold nanoparticles (GNPs) were prepared according to Ali et al. [16]. The colloidal sol was characterized by Hitachi 7100 transmission electron microscope and PerkinElmer Lamda $25 \mathrm{UV}$-vis spectroscopy. The average size of the particles was assigned to $3 \pm 0.2 \mathrm{~nm}$ in diameter by measuring 500 particles [16]. The approximate number and concentration of the particles were determined according to Haiss et al. and were found to be $2.01 \times 10^{11} \mathrm{NPS} \mu \mathrm{L}^{-1}$ and $335 \mathrm{pmol} \mathrm{mL}^{-1}$ [22].

2.3. Preparation of Hybrid Nanobioprobe. The custom-made probes were mixed with GNPs in a ratio of $3: 1$, and the mixture was incubated overnight at $20^{\circ} \mathrm{C}$ in a shaking water bath. The oligoconjugated particles were aged and purified according to Maxwell et al. [15]. The average number of attached oligoprobe per particle was determined by 2 mercaptoethanol digestion following Maxwell and coworkers [15]. The approximate ratio of the single-to-double probebound particles was $1: 1$.

2.4. Preparation of Burger Meats. Separate aliquots of $500 \mathrm{~g}$ of pork-beef binary admixtures were prepared by mixing fresh pork and beef in a ratio of 100:0, 50:50, 25:75, $10: 90,5: 95,1: 99$, and $0: 100(\mathrm{w} / \mathrm{w})$. The burger meats were prepared according to Ali et al. [3]. Briefly, to a $500 \mathrm{~g}$ portion of deboned minced mixed meats of the above composition, $1 \mathrm{~g}$ finely chopped onion, $1 \mathrm{~g}$ of egg, $6 \mathrm{~g}$ of finely chopped sundried tomato, one teaspoon of cumin seed, and $1 / 4$ teaspoon of cayenne pepper were added and mixed well. Each mixture was divided into four equal portions and each portion, was given a burger shape. The produced burger was kept in a fridge for $1 \mathrm{~h}$ and then grilled on both sides in an electrical oven at $220^{\circ} \mathrm{C}$ for $15 \mathrm{~min}$.

2.5. Calibration and Validation Standard. The calibration set was prepared by spiking $1,3,5,10,25$, and $50 \%(\mathrm{w} / \mathrm{w})$ of pork in beef burger meats. Burger meats of $100 \%$ pork and $100 \%$ beef were also formulated to see the differences in fluorescence signal. A different set of burgers was prepared with similar composition for the validation or prediction experiment [3]. Both the calibration and validation sets were prepared in triplicates.

2.6. DNA Extraction. For DNA extraction, $1 \mathrm{~mL}$ of cell and tissue lysis solution (Epicenter Biotechnologies, Madison, USA) was added to a $100 \mathrm{mg}$ portion of finely chopped burger meats and was incubated in a shaking water bath at $65^{\circ} \mathrm{C}$ for $12 \mathrm{~h}$. The subsequent steps of the extraction protocol were performed according to the Epicenter Biotechnologies. The purity and concentration of the extracted DNA samples were determined by spectrophotometric analysis (Biophotometer, Eppendorf, Germany) of absorbance at $\mathrm{A}_{260 / 280}$ and $\mathrm{A}_{260 \mathrm{~nm}}[3,6,16-19]$.

2.7. Specificity and Sensitivity of the Hybrid Nanobioprobe. An aliquot of the purified nanobioprobe was diluted to $10 \mathrm{pmol} \mathrm{mL}^{-1}\left(9.01 \times 10^{12}\right.$ copies $\left.\mathrm{mL}^{-1}\right)$ with hybridization 
TABLE 1: Oligonucleotide sequences used in the study.

\begin{tabular}{lc}
\hline Name & Sequences $\left(5^{\prime} \rightarrow 3^{\prime}\right)$ \\
\hline Probe & TMR $^{\mathrm{a}}-\mathbf{A}_{6} \mathrm{CTGATAGTAGATTTGTGATGACGTAG-A}_{6}\left(\mathrm{CH}_{2}\right)_{6} \mathrm{SH}$ \\
Complementary target & CTACGGTCATCACAA ATCTACTATCAG $^{\text {Noncomplementary target }}$ \\
Single-mismatched target & ACGTAACTGCTGTGGCCTGGTCGCTGA \\
\hline
\end{tabular}

a 6-Carboxy tetramethyl rhodamine flanked by hexyl A $\left(\mathrm{A}_{6}\right)$ spacer, ${ }^{\mathrm{b}}$ mismatched base.

buffer ( $90 \mathrm{mM} \mathrm{KCl,} 10 \mathrm{mM}$ Tris, $\mathrm{pH} 8$ ) [14]. To determine specificity, the hybrid probes were incubated with a 4fold excess $\left(60 \mathrm{pmol} \mathrm{mL}^{-1}\right.$ and $3.6 \times 10^{13}$ copies $\left.\mathrm{mL}^{-1}\right)$ of complementary, noncomplementary, and single-mismatch targets (Table 1 ) at $70^{\circ} \mathrm{C}$ for 5 min to allow strand separation and then at $40^{\circ} \mathrm{C}$ for $30 \mathrm{~min}$ to allow hybridization.

2.8. Specificity and Sensitivity in Mixed Biological Samples. The extracted total DNA $\left(500 \mu \mathrm{g} \mathrm{mL}^{-1}\right)$ was digested with AluI (New England Biolabs, UK) restriction enzymes to create fragments of decisive lengths that could easily match with the size and length of the developed nanobioprobe. The fragments that are produced under natural heat or pressureinduced degradation may not be suitable for biosensor-based detection due to their uncontrolled sizes and shapes. The digestions were performed in a total volume of $1 \mathrm{~mL}$, containing $600 \mu \mathrm{L}$ of total DNA, $200 \mathrm{U}$ of restriction enzymes, and $100 \mu \mathrm{L}$ of digestion buffer (New England Biolabs, UK) for $1 \mathrm{~h}$ at $37^{\circ} \mathrm{C}$ in a shaking water bath. After $1 \mathrm{~h}$, nonspecific digestion was stopped by heating the mixture for $10 \mathrm{~min}$ at $65^{\circ} \mathrm{C}$ that inactivates the enzymatic functions of $A l u \mathrm{I}[6]$. The digestions were confirmed by electrophoresis on 3\% agarose gel. The hybridization reaction was performed in a total volume of $2.5 \mathrm{~mL}$ in triplicates with $10 \mathrm{pmol} \mathrm{mL}^{-1}$ of probe and $60 \mu \mathrm{g} \mathrm{mL} L^{-1}$ of $A l u$ I-digested mixed DNA.

2.9. Fluorescence Measurement. The emission spectra were collected in $10 \mathrm{~mm}$ cuvette with $2 \mathrm{~mL}$ volume in PerkinElmer LS55 fluorescence spectrometer with excitation at $545 \mathrm{~nm}$. Each spectrum was an average of 5 scans with the speed of $200 \mathrm{~nm} \mathrm{~min}{ }^{-1}$ and $5 \mathrm{~nm}$ slit widths. The background was subtracted by replacing sample with $2: 1$ ratio of $10 \mathrm{mM}$ PBS and hybridization buffer. In order to see the hybridization kinetics, a series of fluorescence spectra were obtained in triplicates, and average fluorescence intensity at $579 \mathrm{~nm}$ was plotted as a function of target concentration.

\section{Results and Discussions}

3.1. Detection and Quantification Mechanisms. The operation and quantification principles of the hybrid nanobioprobe are represented in Figure 1. Earlier studies reported that hybrid materials composed of single-stranded DNA (ssDNA), covalently linked to a small gold nanoparticle (2 $3 \mathrm{~nm}$ in diameter) via sulfur-gold bond at one extremity and a fluorescent dye to the other, can assume one of the two distinct conformations: (1) a constrained conformation with a stem-loop or arch-like appearance before target binding or (2) a straight conformation with a rod-like appearance after target binding. In the closed structure, the fluorophore and the GNP are held in close proximity, and the fluorescence is quenched by nonradiative energy transfer from fluorophore to the metal. Conversely, in the open state, the fluorophore is far enough $(>2 \mathrm{~nm})$ from the metal particle to emit fluorescence [14-16]. As such, we assumed that the degree of fluorescence emission depends on the degree of target binding. The maximum fluorescence is observed when the probe is saturated with the targets, and the base-line fluorescence is realized in the absence of any targets. A relationship might be found if fluoresce intensity is plotted against the target concentration, and such a relationship may be used to determine the target DNA concentration.

3.2. Specificity of the Hybrid Nanobiosensor. The fluorescence spectra of $10 \mathrm{pmol} \mathrm{mL}^{-1}$ porcine nanobioprobe with 4 -fold molar excess $\left(60 \mathrm{pmol} \mathrm{mL}^{-1}\right)$ of complementary (blue curve: top one), single mismatch (red curve: 2nd from the top), noncomplementary targets (pink curve: 3 rd from the top) and no targets (green curve: bottom one) are shown in Figure 2. Only base-line fluorescence was observed with the noncomplementary targets. However, single-mismatched targets (2nd from the top) lost 60-70\% observed fluorescence of the perfectly matched targets. Thus, it clearly demonstrated that the fabricated nanobioprobe was highly specific in discriminating complementary, noncomplementary, and single-mismatch sequences. Maxwell et al. [15] achieved 55\% quenching with $2.5 \mathrm{~nm}$ diameter gold nanoparticle probes where gold nanoparticles were produced by reducing sodium borohydride. On the other hand, Dubertret et al. [14] achieved 75\% reduction of fluorescence intensity with molecular beacon and $1.4 \mathrm{~nm}$ diameter gold nanocrystals. The former group used 4 -fold and the latter 10-fold molar excess of targets, probably to produce crowding effect to realize maximum emission of fluorescence. According to Dubertret et al., the discrimination of perfectly matched and mismatched sequences can be clearly observed if low ionic strength hybridization buffer ( $90 \mathrm{mM} \mathrm{KCl,} 10 \mathrm{mM}$ Tris, $\mathrm{pH} 8.0$ ) is used. However, the gold particles, they used, were too small and unstable above $50^{\circ} \mathrm{C}$. We used highly stable citrate-tannate-coated GNPs with relatively large diameter $(\sim 3 \mathrm{~nm}), 4$-fold, molar excess of targets, and also the low ionic strength hybridization buffer. Thus, we achieved sensitivity which is higher than that of Maxwell et al. [15] and close to Dubertret's [14]. 


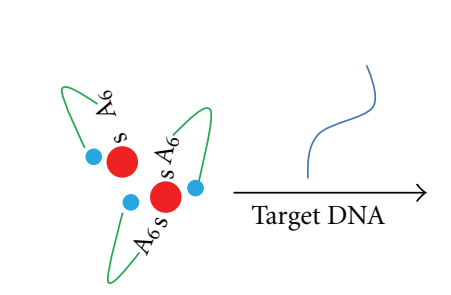

Arch-like conformation: base-line fluorescence
$33.33 \%$ hybridization: $33.33 \%$ fluorescence
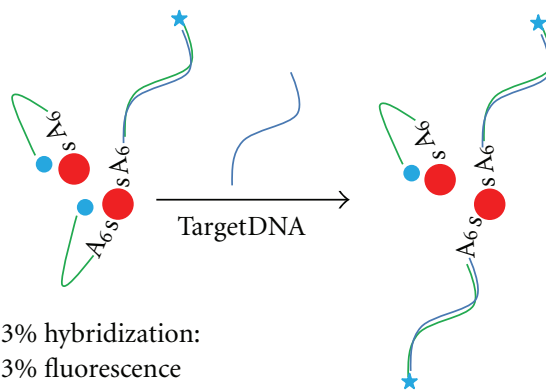

$66.66 \%$ hybridization: $66.66 \%$ fluorescence

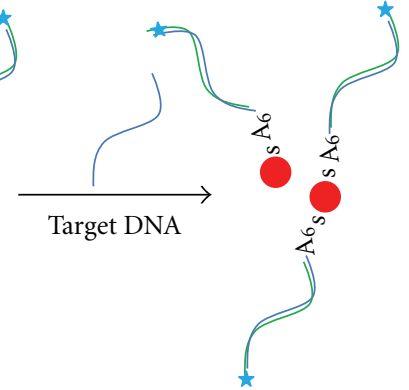

$100 \%$ hybridization: $100 \%$ fluorescence

FIGURE 1: Schematic presentation of the operating and quantification principles of the swine nanobiosensor probes. Three oligonucleotides probes flanked by a hexyl-A spacer and linked to a gold nanocrystal through a gold-thiol bond at one end and fluorophore (TMR) to the other are shown to be self-organized in a constrained arch-like structure where the fluorophore is quenched by the nanoparticle in the absence of any complementary targets. Upon target binding, the closed structure is opened into a rod-like conformation separating the fluorescent dye from the nanoparticle to allow fluorescence emission. The degree of fluorescence emission is shown to proportionate to the degree of target hybridization. Gold nanoparticle is demonstrated by a red sphere. The quenched and emission state of the fluorophore is represented by a sky-blue sphere and a sky-blue star. Single-stranded probe DNA and target DNA are shown by green- and blue-curved line, respectively.

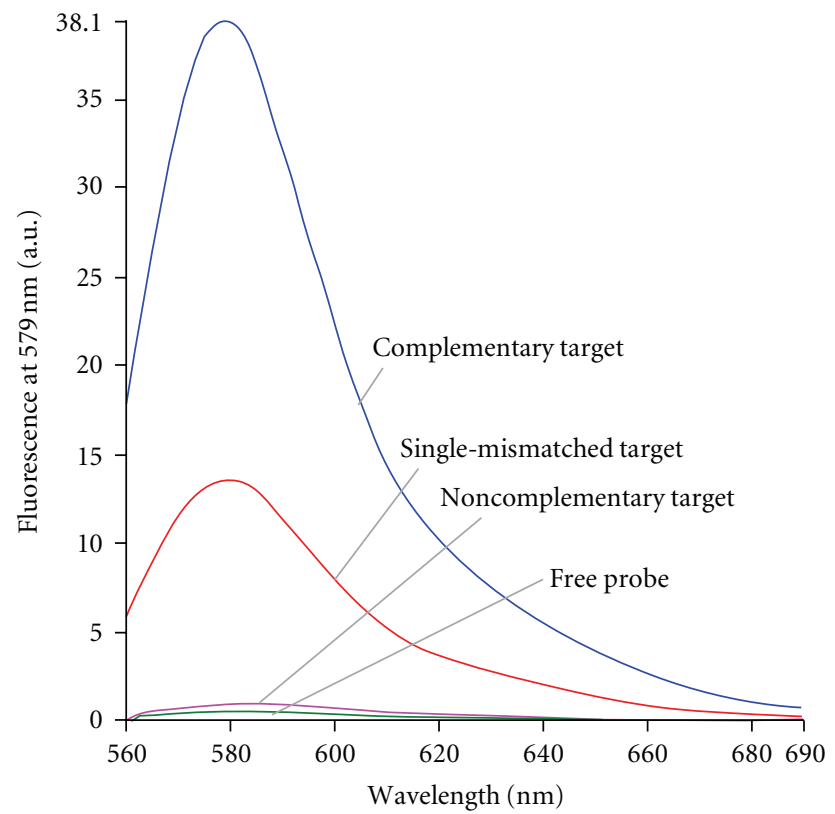

Figure 2: Detection of specific DNA sequences and singlenucleotide mismatches by swine-specific nanobiosensor probes. The corresponding emission spectra collected at $\lambda_{545}$ excitation are shown by labels.

3.3. Pork Detection in Mixed Burger Formulations. The fluorescence spectra of burgers prepared from pork-beef binary admixtures containing various percentages of spiked pork are shown in Figure 3. Fluorescence spectra of commercial burgers of beef, chicken, chevon, and mutton are also demonstrated in the same figure. The swinespecific biosensor probe clearly detected $1 \%$ pork containing $0.6 \mathrm{ng} \mu \mathrm{L}^{-1}$ of swine DNA (yellowish green curve: 7 th from the top) in ready-to-eat burger prepared from pork-beef binary mixtures. This clearly reflects the high sensitivity and specificity of the hybrid nanobioprobe to trace out target DNA in food products processed by severe heat and pressure which degrades DNA $[2,3,5-8]$. No significant change in the sensitivity was observed with uncooked burger preparations (not shown), demonstrating the high stability of the potential targets in processed food products.

Commercial burgers from other species (beef, chicken, mutton, and chevon) showed fluorescence that is comparable to the base-line fluorescence of the free probes (Figure 3 ). We retrieved the nucleotide sequence of cytb genes of these species and aligned with the probe by ClustalW alignment program. The number of mismatches and mismatched nucleotides of each species is shown in the inset of Figure 3. Only the Sus scrofa (pig) species showed 100\% matching, and all the other species showed 5-8 nucleotide (shown in red) mismatching, reflecting the extraordinary specificity of the designed probe, and supporting the experimental findings.

Rodríguez et al. [4] quantified $0.5 \%$ pork adulteration in pork-beef binary mixtures under raw states using TaqMan probe real-time PCR targeting $411 \mathrm{bp}$ template DNA of mt$12 \mathrm{~S}$ ribosomal RNA gene. In contrast, using a comparatively shorter fragments $(<120 \mathrm{bp})$ of different mt genes, Frezza et al. [7] quantitatively detected $0.2 \%$ adulteration of bovine, ovine, swine, and chicken DNAs in feedstuffs by conventional and FRET-based real-time PCR. Recently, Farrokhi et al. [11] detected $0.1 \mathrm{ng}$ pork DNA from commercial meat extracts targeting 234 bp mt-DNA using SYBR green real-time PCR. The detection limit of the molecular beacon real-time PCR assay developed by Yusop et al. [12] that targeted a 119bp $\mathrm{mt}$-cytb gene was $0.1 \%(\mathrm{w} / \mathrm{w})$ pork in pork-beef binary mixtures under raw states. The highest detection limit of $0.01 \%$ of pork in beef burger has recently been reported by Ali et al. $[3,6]$ who targeted a $109 \mathrm{bp}$ fragment of mt-cytb gene using a TaqMan probe real-time PCR [3] 


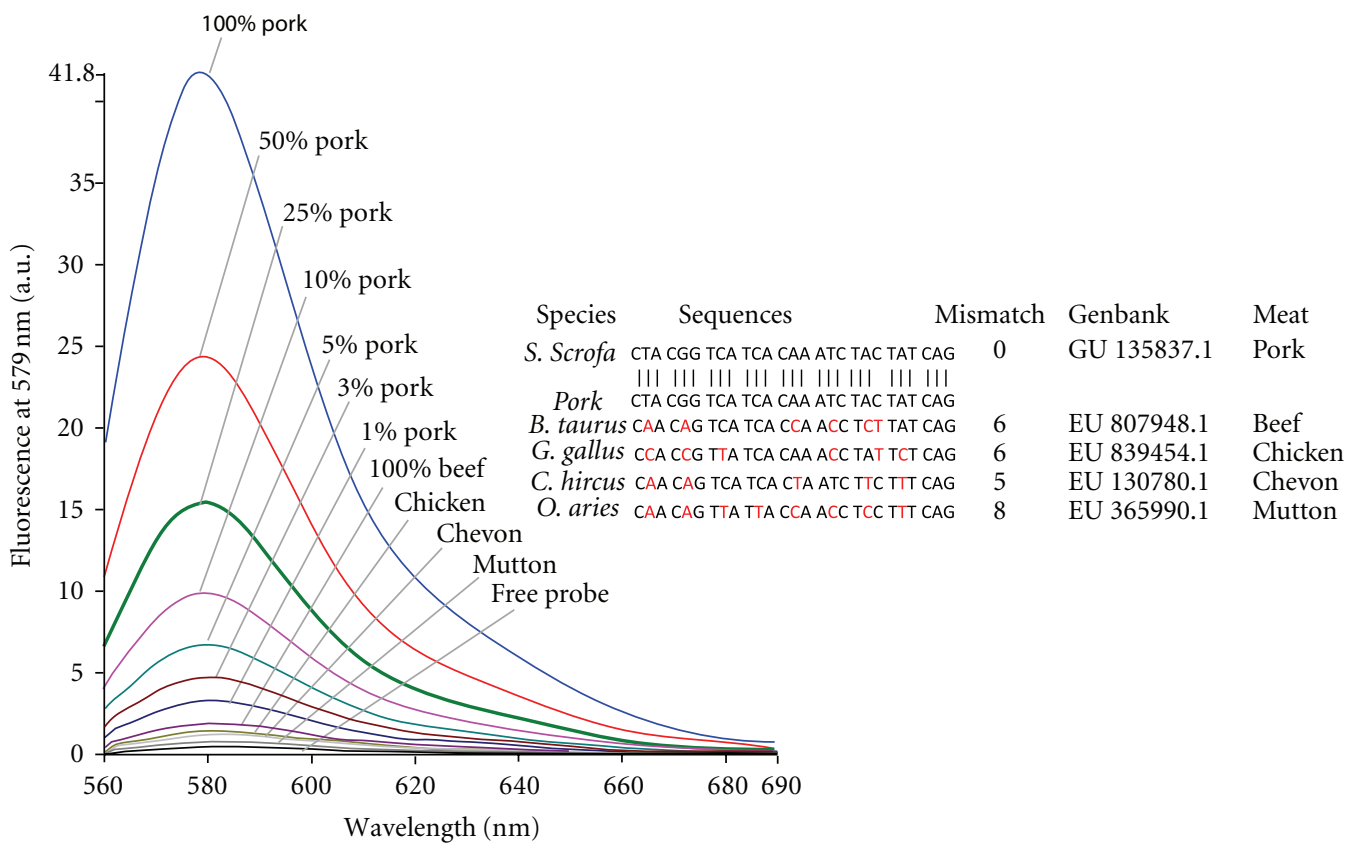

FIGURE 3: Pork detection in ready-to-eat mixed (pork-beef) and commercial burgers of various species. The corresponding emission spectra collected at $\lambda_{545}$ excitation are shown by labels. The inset is the comparison of nucleotide sequences of different species with swine oligoprobe. The mismatched bases are shown in red.

and conventional PCR coupled with microfluidic analysis of the amplified PCR products [6]. While these studies clearly demonstrate improved sensitivity with the reduction of the length of template DNA, too much reduction of the template DNA length is reported to compromise specificity, making the PCR assay unreliable [2, 5]. Additionally, the PCR assays as short as $27 \mathrm{bp}$ cannot be possible as they reflect the equivalence of the size of a PCR primer [113, 20]. Thus, although the detection limit of this assay is far below the conventional and real-time PCR, still the assay has important applications for the detection of shorterlength nucleic acid targets which can survive in the harsh conditions that extensively breakdown DNA into smaller fragments causing amplification failure in PCR reactions $[3,6]$. In short-length (15-30 nucleotides) nucleic acids, such as microRNAs, detection is increasingly important in the diagnosis of cancer and other hereditary diseases at an earlier stage, and the present assay is a suitable candidate for this job [20].

Conventional and real-time PCR assays not only have limitations in detecting short-length nucleic acid targets, but also incur huge cost of instrumentations and consumables and involves laborious electrophoresis and handling of hazardous chemicals such as ethidium bromide [16-19]. In contrast, the present method only involves the initial cost of fluorescence spectrophotometer, reusable cuvette, and fluorescence-labeled probe. GNP preparation is easy and also commercially available at reasonable prices.

Detection of pork in meat products by Fourier transform infrared spectroscopy is interesting as it apparently looks simple and does not involve huge cost that is incurred by real-time PCR [9]. However, the method is flawed by itself as it depends on the analysis of fat which can be extensively manipulated during the cooking process $[3,6]$. Colorimetric detection of PCR amplified and nonamplified swine genomic DNA in a mixed background $[18,19]$ is quite interesting because it does not need any instrument, and detection is also rapid. However, the method is solely qualitative, cannot provide any quantitative information, and also suffers from the interference of single-stranded nucleic acid species. Quantification of specific nucleic acid species helps to draw a boundary between the permissible and nonpermissible limits of adulteration in food analysis and also to monitor the progression of infectious and hereditary diseases in molecular diagnostics [3]. The present assay has a strong potential to be used for these purposes because of its simplicity and lower cost compared with the other existing methods such as real-time PCR.

3.4. Hybridization Kinetics and Target Quantification. When the logarithmic value of AluI-digested target DNA (\% w/w) was plotted against the fluorescence intensity at a fixed concentration of nanobioprobe $\left(10 \mathrm{pmol} \mathrm{mL}^{-1}\right)$, a concaveshaped curve reflecting a power relationship $(y=$ $\left.2.956 x^{0.509}\right)$ between the observed fluorescence and target concentration was obtained (Figure 4(a)). The regression coefficient $\left(R^{2}\right)$ of this curve was 0.986 , meaning the dependant variable $(y$-axis $=$ observed fluorescence $)$ can explain $98.6 \%$ values of the independent variable $(x$-axis $=$ target DNA concentration). The plot reflects very little changes in emitted fluorescence at the two extremes demonstrating that at too low concentration of target $(<1 \% \mathrm{w} / \mathrm{w})$, probe-target collision is too low to open the closed structure (Figure 1), and at too high concentration of target $(>100 \% \mathrm{w} / \mathrm{w})$, the 


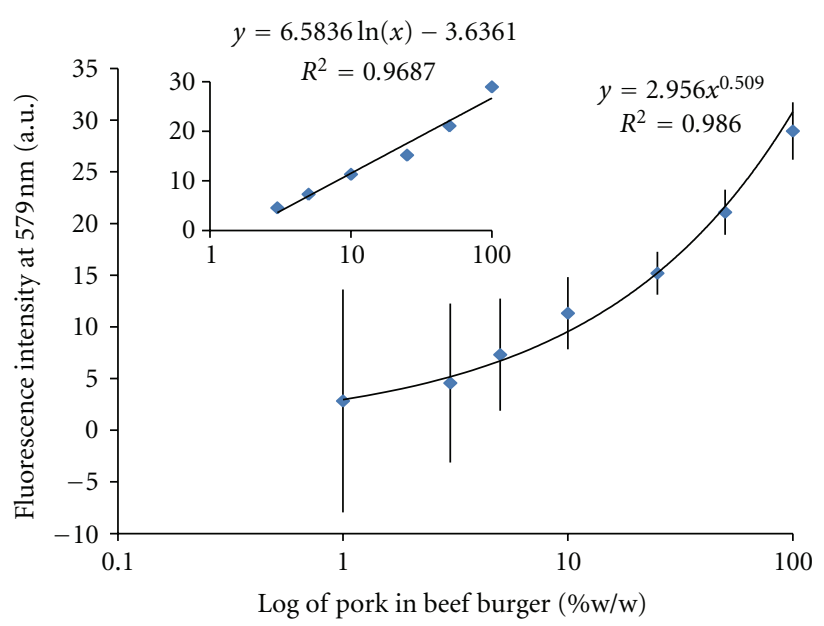

(a)

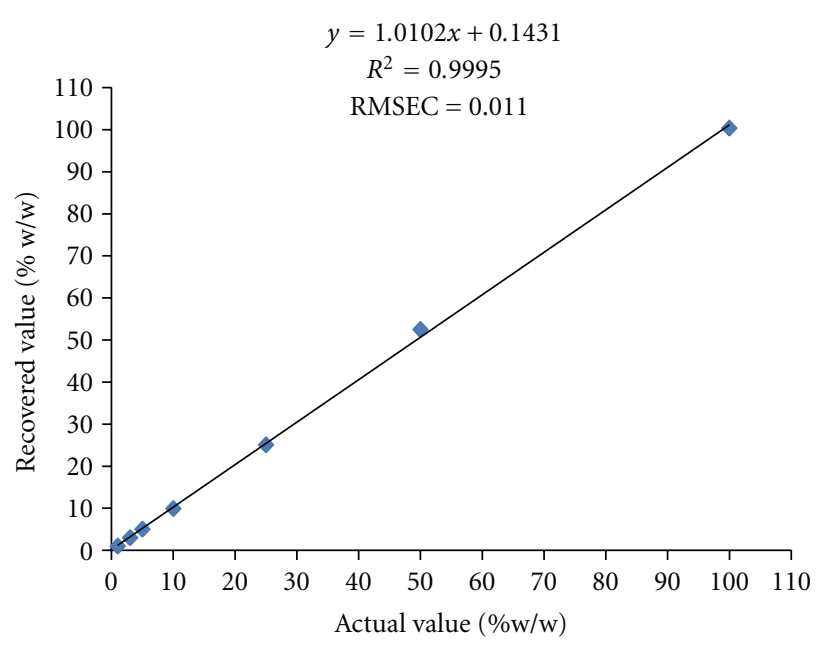

(b)

FIGURE 4: Pork estimation in ready-to-eat beef burgers of $1 \%, 3 \%, 5 \%, 10 \%, 25 \%$, and 100\% pork adulterations (a) and relationship between the actual ( $x$-axis) and recovered values ( $y$-axis) obtained from the standard and validation sets of the above mixtures (b). The standard errors (\%) are shown by the error bars, and the linear part of the curve (3-100\%) is displayed in the inset (a).

probe is supersaturated with the targets resulting in very little or no change in spectral intensity $[16,17]$. At low concentration $(\leq 3 \%)$ of targets, the standard deviation of the observed fluorescence was also higher $(\leq 10 \%)$. However, over a moderate range of target DNA concentration (3-100\%), a linear curve were appeared with $R^{2}=0.968$ (Figure 4(a), inset). This part of the curve also showed $\leq 10 \%$ deviation in interreplicates, interday, and interanalyst analysis, indicating its potential uses in target DNA quantification. When pork concentration $(\% \mathrm{w} / \mathrm{w})$ in beef burger over the range of 5$100 \%$ was plotted against the fluorescence intensity, a linear curve (not shown) with $R^{2}=0.998$ resulted. Linearity was considerably destroyed when less than $5 \%$ pork was used, again reflecting the scarcity of available targets to interact with the probe to open the closed conformation in an efficient manner at low concentration.

We further validated our findings by plotting experimentally determined value against the actual concentration of pork in burger formulations (Figure 4(b)). We observed a linear curve over the range of $1-100 \%$ pork in beef burger with $R^{2}=0.999$. $R^{2}$ value reflects how close the experimentally determined value to the actual concentration. The closer the value to unity, the better the accuracy $[3,9]$. The accuracy of the method as shown by error bar was 90 $95 \%$ over the range of $5-100 \%$ adulteration. However, the accuracy was drastically fallen down $(<90 \%)$ in $\leq 3 \%$ pork mixed in beef burger, reflecting low level of probe-target collision.

\section{Conclusion}

Species-specific hybrid nanobioprobe based on gold nanoparticles was developed to authenticate pork adulteration as low as $1 \%$ in ready-to-consume beef burger preparations with spiked pork. The cross-testing results with various formulations of commercial burgers also revealed the high specificity and sensitivity of the hybrid biosensor for the pork DNA. The hybridization kinetics of the nanobioprobe reflected a power relationship of observed fluorescence with target concentration (1-100\% w/w). However, a linear curve was realized over the moderate concentration of the target (3-100\%) and used to quantify potential targets in processed mixed meat products with more than $90 \%$ accuracy. The method eliminated the need of expensive realtime PCR, time-consuming electrophoresis, and laborious blotting techniques for target DNA identification. We believe our approach would find application in food analysis, genetic screening, biodiagnostics, and forensic investigations.

\section{Acknowledgments}

M. E. Ali is a recipient of Universiti Malaysia Perlis graduate fellowship. The authors like to acknowledge funds "RUGS no. 9031" to Professor Y. B. C. Man and "MOSTI no. 05-0135-SF-1030" to Professor U. Hashim.

\section{References}

[1] R. Meyer, U. Candrian, and J. Lüthy, "Detection of pork in heated meat products by the polymerase chain reaction," Journal of AOAC International, vol. 77, no. 3, pp. 617-622, 1994.

[2] P. D. Brodmann and D. Moor, "Sensitive and semi-quantitative TaqMan real-time polymerase chain reaction systems for the detection of beef (Bos taurus) and the detection of the family Mammalia in food and feed," Meat Science, vol. 65, no. 1, pp. 599-607, 2003.

[3] M. E. Ali, U. Hashim, Th. S. Dhahi, S. Mustafa, Y. B.C. Man, and Md. A. Latif, "Analysis of pork adulteration in commercial burgers targeting porcine-specific mitochondrial cytochrome b gene by TaqMan probe real-time polymerase chain reaction," Food Analytical Methods. In press. 
[4] M. A. Rodríguez, T. García, I. González, P. E. Hernández, and R. Martín, "TaqMan real-time PCR for the detection and quantitation of pork in meat mixtures," Meat Science, vol. 70, no. 1, pp. 113-120, 2005.

[5] H. Hird, J. Chisholm, A. Sanchez et al., "Effect of heat and pressure processing on DNA fragmentation and implications for the detection of meat using a real-time polymerase chain reaction," Food Additives and Contaminants, vol. 23, no. 7, pp. 645-650, 2006.

[6] M. E. Ali, U. Hashim, S. Mustafa, and Y. B. Che Man, "Swinespecific PCR-RFLP assay targeting mitochondrial cytochrome B gene for semiquantitative detection of pork in commercial meat products," Food Analytical Methods. In press.

[7] D. Frezza, V. Giambra, F. Chegdani et al., "Standard and Light-Cycler PCR methods for animal DNA species detection in animal feedstuffs," Innovative Food Science and Emerging Technologies, vol. 9, no. 1, pp. 18-23, 2008.

[8] M. Rojas, I. González, M. A. Pavón et al., "Novel taqman real-time polymerase chain reaction assay for verifying the authenticity of meat and commercial meat products from game birds," Food Additives and Contaminants A, vol. 27, no. 6, pp. 749-763, 2010.

[9] A. Rohman, Sismindari, Y. Erwanto, and Y. B. Che Man, "Analysis of pork adulteration in beef meatball using Fourier transform infrared (FTIR) spectroscopy," Meat Science, vol. 88, no. 1, pp. 91-95, 2011.

[10] A. Doosti, P. Ghasemi Dehkordi, and E. Rahimi, "Molecular assay to fraud identification of meat products," Journal of Food Science and Technology. In press.

[11] R. Farrokhi and R. Jafari Joozani, "Identification of pork genome in commercial meat extracts for Halal authentication by SYBR green I real-time PCR," International Journal of Food Science and Technology, vol. 46, no. 5, pp. 951-955, 2011.

[12] M. H. M. Yusop, S. Mustafa, Y. B. Che Man, A. R. Omar, and N. F. K. Mokhtar, "Detection of raw pork targeting porcinespecific mitochondrial cytochrome $\mathrm{B}$ gene by molecular beacon probe real-time polymerase chain reaction," Food Analytical Methods. In press.

[13] Y. B. Che Man, S. Mustafa, N. F. K. Mokhtar, R. Nordin, and A. Q. Sazili, "Porcine-specific polymerase chain reaction assay based on mitochondrial D-loop gene for the identification of pork in raw meat," International Journal of Food Properties. In press.

[14] B. Dubertret, M. Calame, and A. J. Libchaber, "Singlemismatch detection using gold-quenched fluorescent oligonucleotid," Nature Biotechnology, vol. 19, no. 4, pp. 365-370, 2001.

[15] D. J. Maxwell, J. R. Taylor, and S. Nie, "Self-assembled nanoparticle probes for recognition and detection of biomolecules," Journal of the American Chemical Society, vol. 124, no. 32, pp. 9606-9612, 2002.

[16] M. E. Ali, U. Hashim, S. Mustafa et al., "Nanobiosensor for detection and quantification of DNA sequences in degraded mixed meats," Journal of Nanomaterials, vol. 2011, Article ID 781098, 11 pages, 2011.

[17] M. E. Ali, U. Hashim, S. Mustafa, Y. B. Che Man, and M. H.M. Yusop, "Nanobiosensor for the detection and quantification of specific DNA sequences in degraded biological samples," IFMBE Proceedings, vol. 35, pp. 384-387, 2011.

[18] M. E. Ali, U. Hashim, S. Mustafa, Y. B. Che Man, and K. N. Islam, "Gold nanoparticle sensor for the visual detection of pork adulteration in meatball formulation," Journal of Nanomaterials, vol. 2012, Article ID 103607, 7 pages, 2012.
[19] M. E. Ali, U. Hashim, S. Mustafa et al., "Nanoparticle sensor for label free detection of swine DNA in mixed biological samples," Nanotechnology, vol. 22, no. 19, 2011.

[20] S. Catuogno, C. L. Esposito, C. Quintavalle, L. Cerchia, G. Condorelli, and V. de Franciscis, "Recent advance in biosensors for microRNAs detection in cancer," Cancers, vol. 3, no. 2, pp. 1877-1898, 2011.

[21] J. M. Regenstein, M. M. Chaudry, and C. E. Regenstein, "The Kosher and Halal Food laws," Comprehensive Reviews in Food Science and Food Safety, vol. 2, pp. 111-127, 2003.

[22] W. Haiss, N. T. K. Thanh, J. Aveyard, and D. G. Fernig, "Determination of size and concentration of gold nanoparticles from UV-Vis spectra," Analytical Chemistry, vol. 79, no. 11, pp. 4215-4221, 2007. 

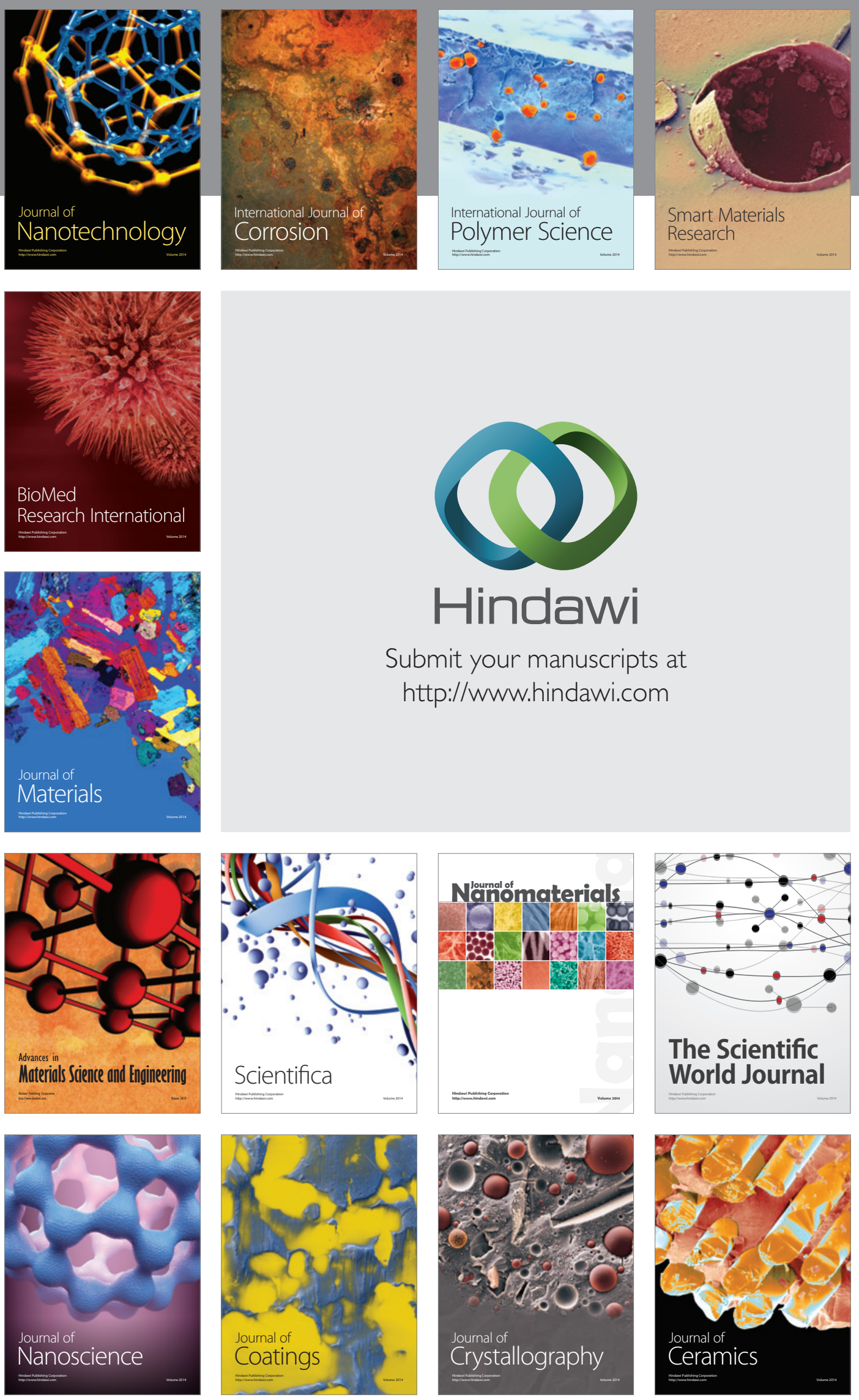

The Scientific World Journal

Submit your manuscripts at

http://www.hindawi.com

\section{World Journal}

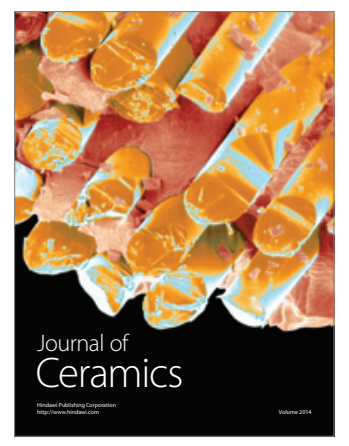

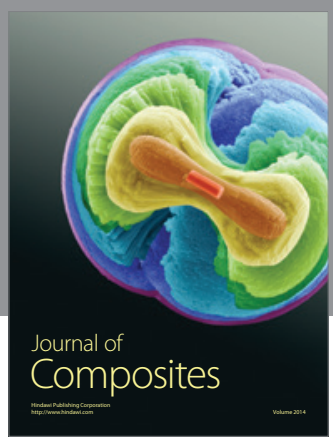
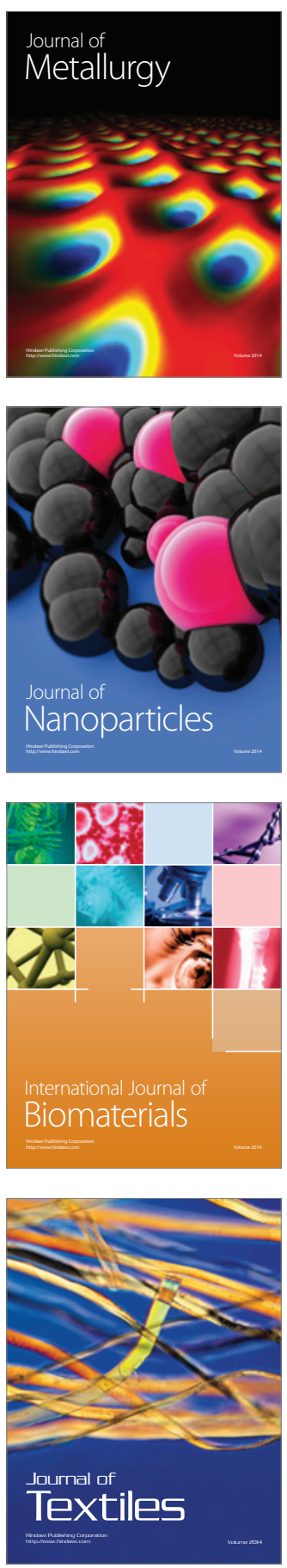